\title{
Anxiety as a risk factor of Alzheimer's disease and vascular dementia
}

\author{
Eva Becker, Claudia Lorena Orellana Rios, Claas Lahmann, Gerta Rücker, Joachim Bauer and
} Martin Boekert

\section{Background}

The aetiology of dementia is not yet fully understood. Stress can have a damaging effect on brain health. The prognostic effect of anxiety is still unclear regarding Alzheimer's disease as well as vascular dementia.

\section{Aims}

To explore the association between anxiety and future dementia.

\section{Method}

Medline, PsycINFO, CINAHL, Web of Science and ALOIS were searched for publications up to 12 January 2018. Longitudinal studies with a follow-up of at least 2 years were included, if the trait or state anxiety had been assessed at baseline. Studies with cognitive impairment at baseline were not included. We used a random effects model to calculate the pooled time to Alzheimer's disease and incidence of vascular dementia.

\section{Results}

Anxiety predicts risk of Alzheimer's disease ( $n=26193$ out of seven studies, hazard ratio1.53, 95\% Cl 1.16-2.01, $P<0.01)$ and vascular dementia ( $n=4916$ out of two studies, odds ratio1.88, $95 \% \mathrm{Cl} 1.05-3.36, P<0.01)$. The pooled hazard ratio regarding risk of Alzheimer's disease was still significant when excluding studies with critical risk of bias ( $n=14110$ out of six studies, hazard ratio $1.35,95 \% \mathrm{Cl} 1.08-1.70, P<0.01$ ).

\section{Conclusions}

Anxiety is a risk factor for both types of dementia. The temporal and functional relation between anxiety and dementia needs investigation in future studies. The protective value of treating anxiety should be explored further.

\section{Declaration of interest}

None.

\section{Keywords}

Anxiety disorders; dementia; aetiology.

\section{Copyright and usage}

(c) The Royal College of Psychiatrists 2018
Alzheimer's disease has a rapidly increasing incidence rate, with an expected doubling of patients every 20 years. ${ }^{1}$ Vascular dementia is the second most common type of dementia after Alzheimer's disease. ${ }^{2}$ The recent prevalence of Alzheimer's disease was estimated at $4.2 \%$ in the worldwide population above age 65 years, ${ }^{3}$ whereas about $1 \%$ have a diagnosis of vascular dementia. ${ }^{4}$ In particular, the aetiology of Alzheimer's disease is not yet fully understood. Because of its enormous personal and global impact, modifiable risk factors need to be identified as soon as possible. The association between anxiety and cognitive decline/dementia has been discussed recently. ${ }^{5}$ Various anxiety-associated factors like inflammation and oxidative stress are linked to the pathogenesis of both types of dementia. ${ }^{6}$ Anxiety is characterised by enduring anticipation and permanent neurotoxic distress. ${ }^{7}$ Especially in old age, neurons are susceptible to the damaging effects of glucocorticoids. ${ }^{8}$ Therefore, the occurrence of anxiety might be a preventable risk factor for dementia when still young; however, bearing in mind the long preclinical phase of Alzheimer's disease, ${ }^{9}$ it could accelerate a destructive chain reaction at an advanced age. ${ }^{10}$ We aim to explore the significance of this association by pooling the evidence yielded from longitudinal studies with a minimum follow-up of 2 years and observance of healthy samples to avoid reversed causality and confounding factors. The scope of this systematic review comprises anxiety disorders, unspecified anxiety symptoms and trait anxiety. For the first time, we not only investigate the predictive value of a broad spectrum of anxiety phenomena, but also differentiate between Alzheimer's disease and vascular dementia.

\footnotetext{
${ }^{\dagger}$ This article originally stated that Eva Becker was a Doctor of Science. This has now been correctly attributed to Gerta Rücker and an erratum published.
}

\section{Method}

This systematic review and meta-analysis was conducted according to the recommendations of the Preferred Reporting Items for Systematic Reviews and Meta-Analyses statement, ${ }^{11}$ the Meta-analysis of Observational Studies in Epidemiology statement ${ }^{12}$ and the Cochrane Handbook of Systematic Reviews of Interventions. ${ }^{13}$

\section{Search strategy}

We searched the databases MEDLINE, all databases from the Web of Science, PsycINFO, CINAHL and ALOIS for relevant publications on 16 June 2016 and updated the procedure on 16 June 2017 and 12 January 2018. We did not set any constraints. The strategy combined related terms of anxiety and dementia (Supplementary Appendix 1 available at https://doi.org/10.1192/bjp.2019.173). Reference lists of relevant reviews were also screened. The search was rounded up by contacting eight leading authors to identify unpublished data.

\section{Selection criteria}

Studies were eligible if they were observational cohort studies or case-control studies with a period of at least 2 years. We only included original work. References were excluded if there was no evidence of any psychological or neuropsychological test or psychiatric diagnostics. Anxiety needed to be assessed distinctly. We further excluded descriptive studies and qualitative research. Participants had to be free of cognitive impairment, systemic and any other psychiatric disorders than anxiety disorders at baseline. Diagnosis of Alzheimer's disease and vascular dementia needed to be based on diagnostic criteria according to the DSM- $5^{14}$ or ICD$10{ }^{15}$ Whenever studies referred to the same cohort, a longer 
follow-up or look-back period was the decisive factor, ahead of population size.

\section{Data extraction}

A physician (E.B.) and a psychologist (C.L.O.R.) screened abstracts independently. Methodological, clinical and statistical data were collected extensively (Supplementary Appendix 2). Missing data regarding study characteristics, assessment of quality and meta-analysis were requested from the authors. Included studies were rated with the weight of evidence framework ${ }^{16}$ (Supplementary Table 1). It is based on the evaluation of three criteria: methodological quality, methodological relevance and topical relevance. Relevance criteria are customised to match the specific review question. Quality indicators of non-randomised studies were evaluated by use of the Newcastle-Ottawa Scale. ${ }^{17}$ Risk of bias was rated with the Risk of Bias in Non-randomised Studies - of Interventions (ROBINS-I) tool. ${ }^{18}$

\section{Statistical analysis}

We used the generic inverse variance method with a random-effects model to calculate the pooled time to Alzheimer's disease and incidence of vascular dementia. ${ }^{19}$ Whenever available, the reported hazard ratios and odds ratios from fully adjusted models were preferred. Distinct risk estimates were synthesised in separated groups with $95 \%$ confidence intervals. ${ }^{20}$ Binary or continuous data of the independent variable were provided. The sensitivity analysis explored the effect of pooled studies with lowest risk of bias. Potential publication bias was investigated by inspecting funnel plots. R software was used for the conduction of all analysis and graphics (version $3.4 .0)^{21,22}$

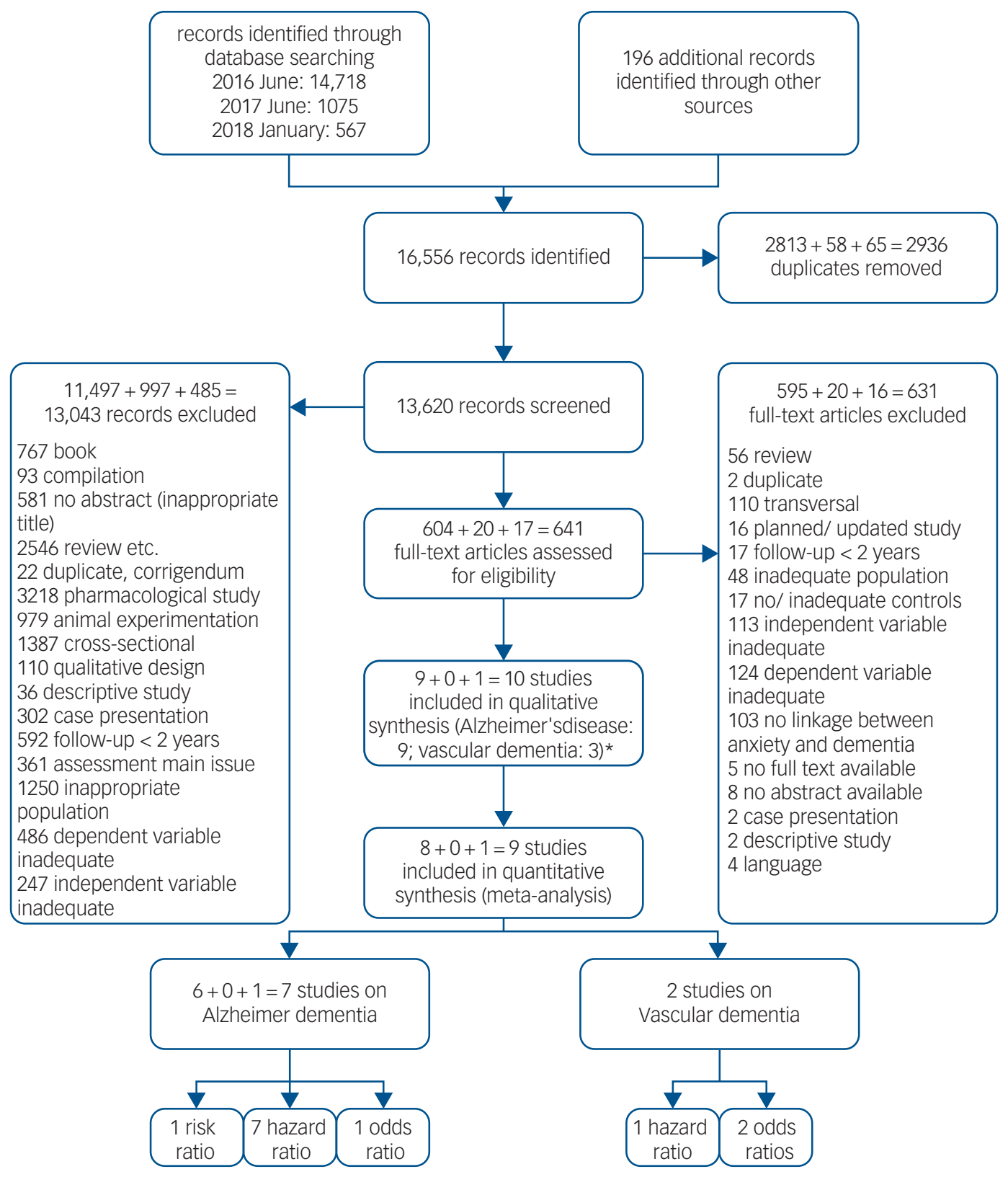

Fig. 1 Preferred Reporting Items for Systematic Reviews and Meta-Analyses flow diagram. * indicates that two studies were eligible for both outcomes. 


\section{Results}

\section{Study selection}

From 16556 records identified by systematic database search $(n=16360)$ and hand-search $(n=196), 13620$ records were left after de-duplication (Fig. 1), and 641 full-texts were checked on inclusion. Some titles were not available (Supplementary Appendix 3). Ten articles met inclusion criteria, ${ }^{23-33}$ with two studies being eligible for both outcomes. ${ }^{30,33}$ One study was identified by checking the reference lists. ${ }^{27}$ We exchanged one paper ${ }^{23}$ because of a more recent version ahead of publication. ${ }^{24}$ Only nine risk ratios from nine studies were left for quantitative analysis because of inappropriate risk ratios with regard to the meta-analysis. Bruijn $e a^{25}$ analysed data about unspecified anxiety symptoms and anxiety disorders from the same participants, who had been assessed at two different follow-ups. The results referring to the earlier part of the study were selected for quantitative analysis.

\section{Anxiety and risk of Alzheimer's disease}

Study characteristics

Study characteristics and risk estimates are shown in Table 1 and Supplementary Table 2. Results of critical appraisal are available online (Supplementary Tables 3 and 4).

Nine studies presented risk estimates regarding Alzheimer's disease. Sample sizes ranged from $185^{29}$ to $12083 .^{24}$ The studies as a whole comprised 37508 people. There was one case-control study. ${ }^{27}$ Mean follow-up time differed between three $e^{29,32}$ and 11 years. ${ }^{25,31}$ As an exception, Zilkens et $a l^{33}$ looked back up to 40 years. Two studies concentrated more or less on a middle-aged population, ${ }^{31,33}$ whereas the remaining studies predominantly included older people, with two studies accepting participants aged $>75$ years only. ${ }^{27,29}$

Two studies focused on trait anxiety assessed by the Revised NEO Personality Inventory. ${ }^{31,32}$ Unspecified anxiety symptoms were screened at baseline in five studies. ${ }^{24,25,28-30}$ Each study used a different instrument (Supplementary Table 2). Two studies checked evidence of anxiety disorders by psychiatric examination at baseline $e^{25}$

\begin{tabular}{|c|c|c|c|c|c|c|}
\hline Author year & Project, setting & $\begin{array}{l}\text { Total at baseline; } \\
\text { female (\%) }\end{array}$ & $\begin{array}{l}\text { Mean age in } \\
\text { years (s.d.); } \\
\text { range in years }\end{array}$ & $\begin{array}{l}\text { Anxiety scale; } \\
\text { prevalence of } \\
\text { anxiety (\%) }\end{array}$ & $\begin{array}{l}\text { Follow-up in } \\
\text { years (s.d.); } \\
\text { range in years }\end{array}$ & Risk ratio ${ }^{a}(95 \% \mathrm{Cl})$ \\
\hline Burke $2016^{24}$ & $\begin{array}{l}\text { NACC, consecutive + } \\
\quad \text { volunteers }\end{array}$ & $12083 ; 64.1$ & $\begin{array}{l}71.05(10.86) ; \\
\text { n.a. }\end{array}$ & NPI-Q; 8.04 & $4.2(6.3) ; 0.6-9.5$ & $\begin{array}{l}\text { Alzheimer's disease: } \\
\text { hazard ratio } 2.28 \\
(1.75-2.97)\end{array}$ \\
\hline $\begin{array}{l}\text { De Bruijn } 2014^{25} \\
\text { sample 1/ } \\
\text { sample } 2\end{array}$ & $\begin{array}{l}\text { Rotterdam Study, population- } \\
\text { based }\end{array}$ & 2708/3069; 45.2/39.0 & $\begin{array}{c}68.6 / 75.5(8.5 / \\
6.2) ;>55\end{array}$ & $\begin{array}{l}\text { HADS/DSM-IV; } \\
12.3 / 8.7\end{array}$ & $\begin{array}{c}11.8 / 5.8 \text { (5.0/ } \\
1.9) ; \text { n.a. }\end{array}$ & $\begin{array}{l}\text { Alzheimer's disease: } \\
\text { hazard ratio } 1.11 \\
(0.66-1.52) / 0.92 \\
(0.58-1.45)\end{array}$ \\
\hline Gallacher $2009^{26}$ & $\begin{array}{l}\text { Caerphilly Prospective Study, } \\
\text { population-based }\end{array}$ & $2358 ; 0$ & n.a.; 45-67 & $\begin{array}{l}\text { STAI-Trait Scale; } \\
\quad 5.4\end{array}$ & $\begin{array}{l}17 \text { (1.3); } \\
\text { maximum } \\
20\end{array}$ & $\begin{array}{l}\text { Vascular dementia: } \\
\text { odds ratio } 2.79 \\
(0.6-13.06)\end{array}$ \\
\hline Jessen $2012^{27}$ & $\begin{array}{l}\text { German Study on Ageing, } \\
\text { Cognition and Dementia in } \\
\text { primary care patients } \\
\text { (selected randomly) }\end{array}$ & $1061^{\text {b. }} ; 58.3$ & $79.8(3.6) ;>75$ & $\begin{array}{l}\text { Polar question } \\
\text { about worry; } \\
24.6\end{array}$ & $4.5 ; 1.5-6.0$ & $\begin{array}{c}\text { Alzheimer's disease: } \\
\text { hazard ratio } 2.44 \\
(1.44-4.14)\end{array}$ \\
\hline Lobo $2017^{28}$ & $\begin{array}{l}\text { Dementia and Depression in } \\
\text { Zaragosa, Spain }\end{array}$ & 4803; n.a. & n.a.; >55 & AGECAT & 5 & $\begin{array}{l}\text { Alzheimer's disease: } \\
\text { hazard ratio } 3.47 \\
(1.35-8.94)\end{array}$ \\
\hline Palmer $2007^{29}$ & $\begin{array}{l}\text { Kungsholmen Project, } \\
\text { population-based }\end{array}$ & $185 ; 84.9$ & $84(5.1) ; 75-95$ & CPRS; 24.9 & $3.4(0.6) ;$ n.a. & $\begin{array}{l}\text { Alzheimer's disease: } \\
\text { risk ratio } 1.1 \\
(0.5-2.3)\end{array}$ \\
\hline Stewart $2015^{30}$ & primary care & $3082 ; 69$ & 68.7 (6.9); n.a. & PRIME-MD; 43.6 & 8; n.a & $\begin{array}{l}\text { Alzheimer's disease: } \\
\text { hazard ratio } 1.30 \\
(1.04-1.63) \\
\text { Vascular dementia: } \\
\text { hazard ratio } 1.02 \\
(0.71-1.47)\end{array}$ \\
\hline $\begin{array}{l}\text { Terracciano } \\
\qquad 2014^{31}\end{array}$ & $\begin{array}{l}\text { Baltimore } \\
\text { Longitudinal Study of } \\
\text { Aging, consecutive } \\
\text { (clinical) + volunteers }\end{array}$ & $1671 ; 49.4$ & $56.5(16) ;>20$ & NEO-PI-R; n.a. & $12(6) ; 1-22$ & $\begin{array}{l}\text { Alzheimer's disease: } \\
\text { hazard ratio } 1.34 \\
(1.08-1.66)\end{array}$ \\
\hline Wilson $2011^{32}$ & $\begin{array}{l}\text { Rush Memory and Aging } \\
\text { Project, population- } \\
\text { based }^{c}\end{array}$ & $785 ; 76.3$ & 80.7 (7.4); n.a. & NEO-PI-R; n.a. & 3.4 (1.4); n.a. & $\begin{array}{l}\text { Alzheimer's disease: } \\
\text { hazard ratio } 1.05 \\
(1.01-1.09)\end{array}$ \\
\hline Zilkens $2014^{33}$ & $\begin{array}{l}\text { Cases: Western Australian } \\
\text { Mental Health Information } \\
\text { System, etc.; controls: } \\
\text { selected randomly }\end{array}$ & $\begin{array}{l}\text { Alzheimer's disease } \\
\text { (vascular dementia) } \\
\text { cases/controls: } 5565 \\
\text { (1280)/5565 (1280) }\end{array}$ & $\begin{array}{l}8.7(4.7) ;<65 \\
\text { years at the } \\
\text { time of } \\
\text { diagnosis }\end{array}$ & $\begin{array}{l}\text { ICD code F41; } \\
\text { cases: } 2.8 \\
\text { controls: } 1.5\end{array}$ & $\begin{array}{c}20.4(10.4) \\
10-40\end{array}$ & $\begin{array}{l}\text { Alzheimer's disease: } \\
\text { odds ratio } 1.08 \\
(0.81-1.45) \\
\text { Vascular dementia: } \\
\text { odds ratio } 1.76 \\
(0.94-3.30)\end{array}$ \\
\hline
\end{tabular}


or exploration of medical records. ${ }^{33}$ Only Jessen et $a l^{27}$ analysed memory complaints and dementia worry in particular.

The prevalence of anxiety was reported in seven of nine studies. Prevalence varied between $2.15^{33}$ and $44 \% .^{30}$ The pooled prevalence of anxiety across seven studies was $9.4 \%$. Depressive symptoms or depression were present in $9.3 \%$ of all participants. Six of nine studies assessed the role of depression as a confounding variable within regression analysis. Both anxiety and depression can be considered as independent risk factors. Coincidence of anxiety and depression is accompanied by a cumulative hazard ratio. ${ }^{30}$

Only one study showed overall critical risk of bias ${ }^{24}$ (Supplementary Table 3 ). With regard to the only retrospective study, recall bias was avoided by studying files to detect presence of anxiety disorders. ${ }^{33}$ Controls were randomly selected here. ${ }^{33}$

Three studies were based on epidemiological studies and therefore rated as being representative of the general population. ${ }^{25,28,29}$ Other studies included patients drawn consecutively or selected randomly from clinics ${ }^{24}$ and primary care, ${ }^{27,30}$ volunteers ${ }^{31}$ and seniors selected from retirement areas. ${ }^{32}$

The weight of evidence of included studies is presented in Supplementary Table 2. Quality was adequate to high in all cases, with three exceptions (Supplementary Table 4). ${ }^{24,28,32}$ Five studies were rated less relevant methodologically because of the shortness of observation periods $s^{24,27,28,30,32}$ and four studies were rated less relevant topically because of exploration of trait anxiety or dementia worry (Supplementary Table 5). ${ }^{26,27,31,32}$

\section{Description of primary studies}

Risk estimates from final regression models are cited from original work.

Both articles investigating trait anxiety ${ }^{31,32}$ report positive associations with regard to Alzheimer's disease (hazard ratio 1.34, 95\% CI 1.08-1.657; hazard ratio1.05, 95\% CI 1.01-1.09). There is no evidence for a systematic correlation between anxiety disorders and Alzheimer's disease. The odds ratio calculated by Zilkens et $a l^{33}$ comprises different ICD diagnoses (odds ratio $1.08,95 \%$ CI $0.81-1.45$ ), whereas Bruijn et $a l^{25}$ provide risk estimates on each type of disorder separately. Neither the result of any of three subanalyses (generalised anxiety disorder, specific phobias, agoraphobia) nor the pooled risk ratio is positively correlated with development of dementia (hazard ratio $0.92,95 \%$ CI $0.58-1.45)$.

Anxiety is a predictive factor in four of six studies that observed individuals aged 65 years and over. ${ }^{24,27,30,32}$

\section{Meta-analysis}

The meta-analysis displays a positive association of anxiety as a predictor of Alzheimer's disease $(n=26193$ out of seven studies, hazard ratio1.53, 95\% CI 1.16-2.01, $P<0.01$ ) (Fig. 2). Two studies are not included because no hazard ratio was calculated. ${ }^{29,33}$

The sensitivity analysis was based on exclusion of the risk estimate reported by Burke et $a l^{24}$ because of highest risk of bias (Supplementary Fig. 1). Pooled hazard ratio was still significant ( $n=14110$ out of six studies, hazard ratio1.35, 95\% CI 1.08-1.70, $P<0.01)$. Some extent of publication bias is apparent when inspecting the corresponding funnel plots (Supplementary Figs. 2 and 3).

\section{Anxiety and risk of vascular dementia}

Study characteristics and risk estimates are shown in Table 1 and Supplementary Table 2. Results of critical appraisal are available online (Supplementary Tables 3 and 4).

\section{Study characteristics}

Three studies investigated vascular dementia. One study analysed 1280 patients with vascular dementia and selected random controls retrospectively. ${ }^{33}$ Stewart et $a l^{30}$ evaluated data from 3082 people who had been recruited and examined consecutively by general practitioners. Gallacher et $a l^{26}$ analysed the development of 1160 males stemming from an epidemiologic study with 2358 participants at baseline. Individuals were followed up for 8 years ${ }^{26}$ and up to 20 years, ${ }^{26}$ whereas Zilkens et $a l^{33}$ drew on information up to 40 years ago. Both Zilkens et $a l^{33}$ and Gallacher et $a l^{26}$ included individuals aged $<65$ years only, whereas participants of the third study were aged 68 years on average. ${ }^{30}$

Intensity of exposition was mixed across studies and assessed with Spielberger's State-Trait Anxiety Inventory with emphasis on trait anxiety, ${ }^{26}$ Primary care evaluation of Mental Disorders for detecting unspecified anxiety symptoms ${ }^{30}$ and ICD criteria for anxiety disorders. ${ }^{33}$ Consequently prevalence rates were $50.4,{ }^{26}$ $44^{30}$ and $2.15 \% .{ }^{33}$ Cardiovascular risk factors and depression were controlled in two analyses, ${ }^{26,30}$ whereas Zilkens et al did not adjust for depression within the regression model. There is serious risk of bias across studies (Supplementary Table 3 ) because of unknown or high drop-out rates, ${ }^{26,30}$ uncontrolled depressive symptoms ${ }^{33}$ and short-term follow-up. ${ }^{30}$ Methodological quality as well as relevance is adequate to high (Supplementary Tables 4 and 5).

\begin{tabular}{|c|c|c|c|c|c|c|}
\hline Study & $\begin{array}{l}\text { estimate of } \\
\text { effect (log) }\end{array}$ & s.e. & $\begin{array}{r}\text { Weight } \\
\text { (fixed) }\end{array}$ & $\begin{array}{l}\text { Weight } \\
\text { (random) }\end{array}$ & $\begin{array}{l}\text { Hazard ratio } \\
\text { Inverse variance weighting, } \\
\text { Fixed + Random, } 95 \% \mathrm{Cl}\end{array}$ & $\begin{array}{c}\text { Hazard ratio } \\
\text { Inverse variance weighting, } \\
\text { Fixed + Random, } 95 \% \mathrm{Cl} \\
\end{array}$ \\
\hline Wilson $2011^{32}$ & 0.05 & 0.0194 & $91.2 \%$ & $19.2 \%$ & $1.05(1.01 ; 1.09)$ & $\begin{array}{lll}+ & \\
+\end{array}$ \\
\hline De Bruijn $2014^{25}$ & 0.10 & 0.2128 & $0.8 \%$ & $3.3 \%$ & $1.11(0.73 ; 1.68)$ & \\
\hline $2014^{27}$ & 0.89 & 0.2694 & $0.5 \%$ & $11.2 \%$ & $2.44(1.44 ; 4.14)$ & \\
\hline Terracciano $2014^{31}$ & 0.29 & 0.1097 & $2.9 \%$ & $17.2 \%$ & $1.34(1.08 ; 1.66)$ & \\
\hline a $2015^{30}$ & 0.26 & 0.1146 & $2.6 \%$ & $17.0 \%$ & $1.30(1.04 ; 1.63)$ & $\mid$ \\
\hline Burke 2 & 0.82 & 0.1349 & $1.9 \%$ & $16.3 \%$ & $2.28(1.75 ; 2.97)$ & $\rightarrow$ \\
\hline Lobo $2017^{28}$ & 1.24 & 0.4823 & $0.1 \%$ & $5.8 \%$ & $3.47(1.35 ; 8.93)$ & \\
\hline \multicolumn{2}{|c|}{ Total (fixed effect, 95\% Cl) } & & $100.0 \%$ & - & $1.09(1.05 ; 1.13)$ & 4 \\
\hline \multicolumn{2}{|c|}{$\begin{array}{l}\text { Total (random effects, 95\% Cl) } \\
\text { Prediction interval }\end{array}$} & & - & $100.0 \%$ & $\begin{array}{r}1.53(1.16 ; 2.01) \\
(0.63 ; 3.72)\end{array}$ & $i$ \\
\hline \multicolumn{6}{|c|}{ Heterogeneity: Tau $^{2}=0.1003 ; \mathrm{Chi}^{2}=54.19, \mathrm{df}=6(P<0.01) ; I^{2}=89 \%$} & 0.2 \\
\hline
\end{tabular}




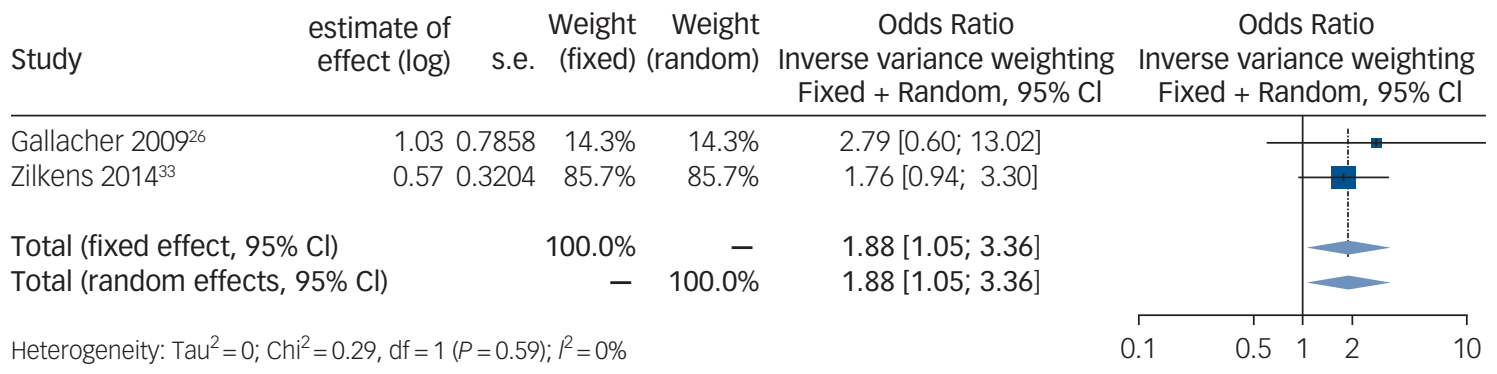

Fig. 3 Forest plot for anxiety as a predictive factor for vascular dementia. Legend: Squares and horizontal lines represent study effects and $95 \%$ $\mathrm{Cl}$, diamonds indicate the combined effect of each model.

\section{Description of primary studies}

Risk estimates from final regression models are cited from original work.

One study reports no association between anxiety and vascular dementia (hazard ratio1.02, 95\% CI 0.71-1.47). ${ }^{30}$ Variables are positively correlated in the remaining two studies, but the results do not reach statistical significance (odds ratio $1.76,95 \%$ CI $0.94-$ $3.30^{33}$ and odds ratio $2.79,95 \%$ CI $\left.0.6-13.06\right) .{ }^{26}$

\section{Meta-analysis}

Synthesis of those studies, which calculated an odds ratio, shows a positive and significant association between anxiety and vascular dementia (Fig. 3) ( $n=4916$ out of two studies, odds ratio 1.88, 95\% CI 1.05-3.36, $P=0.06$ ).

\section{Discussion}

This study presents a systematic review and meta-analysis investigating the association between anxiety and Alzheimer's disease as well as vascular types. We performed a broad search initially including about 16000 records. Ten studies could be included in this systematic review.

Quantitative analysis reveals a positive association between anxiety and both Alzheimer's disease $(n=26193$ out of seven studies; hazard ratio $1.53,95 \%$ CI $1.18-2.01, P<0.01)$ and vascular dementia ( $n=4916$ out of two studies; odds ratio $1.88,95 \% \mathrm{CI}$, 1.05-3.36, $P=0.6$ ). When looking at studies with lowest risk of bias, the association remains positive. Moreover age, gender, education and depression have been controlled in most studies and did not weaken the effect of anxiety on dementia significantly, whereas no study considered sleeping disorders, intake of benzodiazepines or drug misuse as confounding factors.

Size and direction of results are in line with recent findings of other meta-analyses exploring the association between anxiety-related psychiatric disorders, ${ }^{34-36}$ psychosocial factors ${ }^{37}$ and dementia. Pooled risk estimates of cited meta-analyses range from $1.6^{35}$ to $3.1 .^{31}$

\section{Anxiety and Alzheimer's disease}

Two studies endorsed the association between trait anxiety and Alzheimer's disease. ${ }^{31,32}$ Both results were not adjusted for depression, but findings were independent from gender. Personality traits are stable over time. ${ }^{38}$ It is plausible that trait anxiety promotes permanent brain-damaging stress. ${ }^{39}$ Interestingly, personality traits are not correlated to neuropathogenic lesions, ${ }^{32}$ suggesting that reduced cognitive reserve might be a crucial pathomechanism. ${ }^{40,41}$ Both results were not adjusted for depression, so this could have been a source of bias. Nevertheless it means that early treatment could possibly delay or avoid dementia. ${ }^{24}$ This needs further investigation. Bearing in mind that findings were independent from gender, the damaging pathway of anxiety and stress is likely to be independent from sex hormones. Moreover anxiety is not a sufficient explanation why Alzheimer's disease occurs more frequently in women.

Individuals displaying both anxious and depressive symptoms are at higher risk of Alzheimer's disease. ${ }^{30}$ This is plausible according to the cumulative stress hypothesis. ${ }^{42}$ Bearing that in mind, one would expect anxiety disorders to be at least as damaging as trait anxiety and depression because of their intensity and recurrence in many patients. Surprisingly, both studies exploring ICD or DSM diagnoses of anxiety did not find a significant relationship. ${ }^{25,33}$ According to the stress hypothesis, trait anxiety might provoke chronic distress and allostatic load throughout life, whereas anxiety disorders differ in typical age at onset. ${ }^{43}$ The probability of recovery ranges from $37 \%$ (social phobia) to $82 \%$ (panic disorder) within 12 years. ${ }^{44}$ Thus, the effect of specific anxiety disorders on cognitive health might be different because of prognosis. In this systematic review, only one study provided information about subtypes, but no association with regard to Alzheimer's disease was found for generalised anxiety disorder, specific phobia and agoraphobia. ${ }^{25}$

Five of the seven pooled risk estimates stem from study populations with a mean age $>65$ years. Therefore, the result of the performed meta-analysis is influenced by age. The predictive value is probably due to reversed causality or reactive anxiety accompanied by subjective memory impairment in this age group. When considering Alzheimer's disease as a continuum, index age does not play a substantial role. ${ }^{45}$ Anxiety might play a role in the aetiology of, or at least have a catalytic effect on dementia.

Considering the cognitive reserve hypothesis, distinct emotions and behaviours could have a different effect on cognition. For example, anhedonia and withdrawal as core symptoms of depression could lead to adverse effects on brain health by inactivity and reduced stimulation, whereas affirmation of life and lifestyle might be less impaired in people with anxiety disorders. ${ }^{46}$ Melancholia but not comorbid anxiety in patients with depression was found to be a predictive factor with regard to future dementia. ${ }^{47}$

\section{Anxiety and vascular dementia}

Only two cohort studies and one case-control study explored the secondary objective. Two results were integrated in the quantitative synthesis. ${ }^{26,33}$ Depression but not anxiety was associated to future vascular dementia in the remaining study. ${ }^{30}$ Given the minimum number of studies, this result has to be interpreted with caution. Vascular dementia is often accompanied by anxiety disorders. ${ }^{48}$ Therefore the connection between anxiety and vascular dementia could be driven by comorbid cardiovascular disease and risk factors, depression, substance misuse and health-damaging behaviour in general. Anxiety might facilitate vascular damage and dementia via hypercoagulability, atherosclerosis and hypertension. ${ }^{49}$ Included studies controlled cardiovascular risk factors and cardiovascular diseases to a large extent, strengthening the 
assumption that psychological distress is a shared feature within the course of both Alzheimer's disease and vascular dementia and might lead to cognitive decline via adverse effects of cortisol.

\section{Limitations}

Although our search was designed to detect dementia and anxiety in the broadest sense, the search strategy did not include terms for depression and trauma. Thus, we might not have included studies that looked for dimensions of anxiety in depressive and traumatised patients. However, the populations with systemic and other mental diseases than anxiety disorders were excluded intentionally to a great extent to focus this systematic review on studies in which anxiety was the single independent variable to minimise confounding by specific underlying systemic conditions.

Although various databases with different areas of focus were chosen, our systematic review displays an inevitable evidence of publication bias in this particular field of research. One small study $^{29}$ could not be included in our quantitative analysis because no hazard ratio was provided. This study might have reduced the evidence of publication bias.

With regard to the meta-analysis, studies with incompatible risk estimates for both Alzheimer's disease and vascular dementia were excluded. In light of the fact that the excluded studies yielded non-significant results, findings from quantitative analysis must be interpreted with caution. A remarkable amount of heterogeneity and several methodological limitations and inconsistencies across studies might weaken the validity of the positive association found in our meta-analysis. The diversity of different instruments for anxiety is broad, but non-validated tests were applied in only one study. ${ }^{27}$ Validated tests of the independent variable were not performed in an appropriate manner. For example, in one study the Neuropsychiatric Inventory was used in healthy participants. ${ }^{24}$ Another study arbitrary shortened the Comprehensive Psychopathological Rating

Scale and segregated the anxiety items and depression items in a non-authorised manner. ${ }^{29}$ Reporting was incomplete and reduced to a conference paper in two cases. ${ }^{28,30}$ Because of scarceness of longterm studies, we faced risk of reversed causality and recommend the design of fairly long-term studies in the future to avoid this problem.

\section{Implications for the future}

To our knowledge, this meta-analysis is the first to demonstrate a small association between anxiety and specific types of dementia in the sense of a predictive factor. Independently of age, anxiety is likely to damage the brain directly by permanent stress and indirectly by avoiding behaviour, inactive lifestyle and loss of cognitive reserve and resiliency. The preventive potential of treating anxiety and the role of lifestyle should be focused in future research. The question arises whether cognitive-behavioural therapy has the potential to end the vicious circle of worries and memory loss in the elderly population. Furthermore, trait anxiety should be taken seriously at an early age because it might be a modifiable risk factor of future dementia. The temporal or functional relation between anxiety and dementia needs more careful investigation in larger cohort studies with better biomarkers and psychometric measurement.

Eva Becker, Physician, Department of Psychosomatic Medicine and Psychotherapy, Faculty of Medicine and Medical Center, University of Freiburg, Germany; Claudia Lorena Orellana Rios, Psychologist, Department of Palliative Care, Faculty of Medicine and Medical Center, University of Freiburg, Germany; Claas Lahmann, Professor of Psychosomatic Medicine and Psychotherapy, Department of Psychosomatic Medicine Psychosomatic Medicine and Psychotherapy, Department of Psychosomatic Medicine
and Psychotherapy, Faculty of Medicine and Medical Center, University of Freiburg, Germany; Gerta Rücker, DSc, Statistician, Institute of Medical Biometry and Statistics, Faculty of Medicine and Medical Center, University of Freiburg, Germany; Joachim Bauer, Professor of Psychoneuroimmunology, International Psychoanalytic University Berlin, Germany; Martin Boeker, MD, MSc, Computer Scientist, Institute of
Medical Biometry and Statistics, Faculty of Medicine and Medical Center, University of Freiburg, Germany

Correspondence: Eva Becker, Department of Psychosomatic Medicine and Psychotherapy, Faculty of Medicine and Medical Center, University of Freiburg, Hauptstrasse 8, 79108 Freiburg, Germany. Email: eva.becker@neptun.uni-freiburg.de

First received 14 Feb 2018, final revision 26 Mar 2018, accepted 10 May 2018

\section{Supplementary material}

Supplementary material is available online at https://doi.org/10.1192/bjp.2018.173.

\section{References}

1 Prince M, Ali GC, Guerchet M, Yu-Tzu W, Prina M. The global prevalence of dementia. In World Alzheimer Report 2015 (eds G Rees, S Fletcher): 10-29. Alzheimer's Disease International, 2015.

2 O'Brien JT, Thomas A. Vascular dementia. Lancet 2015; 386: 1698-706.

3 Fiest KM, Roberts Jl, Maxwell CJ, Hogan DB, Smith EE, Frolkis A, et al. The prevalence and incidence of dementia due to Alzheimer's disease: a systematic review and meta-analysis. Can J Neurol Sci 2016; 43(Suppl 1): S51-82.

4 Rizzi L, Rosset I, Roriz-Cruz M. Global epidemiology of dementia: Alzheimer's and vascular types. BioMed Res Int 2014; 2014: 1-8.

5 Gulpers B, Ramakers I, Hamel R, Kohler S, Oude Voshaar R, Verhey F. Anxiety as a predictor for cognitive decline and dementia: a systematic review and metaanalysis. Am J Geriatr Psychiatry 2016; 24: 823-42.

6 Machado A, Herrera AJ, de Pablos RM, Espinosa-Oliva AM, Sarmiento M, Ayala A, et al. Chronic stress as a risk factor for Alzheimer's disease. Rev Neurosci 2014; 25: 785-804.

7 Pary R, Matuschka PR, Lewis S, Caso W, Lippmann S. Generalized anxiety disorder. South Med J 2003; 96: 581-6.

8 Fuxe K, Diaz R, Cintra A, Bhatnagar M, Tinner B, Gustafsson J-A, etal. On the role of glucocorticoid receptors in brain plasticity. Cell Mol Neurobiol 1996; 16: 239-58.

9 Dubois B, Epelbaum S, Santos A, Di Stefano F, Julian A, Michon A, et al. Alzheimer disease: from biomarkers to diagnosis. Rev Neurol 2013; 169: 744-51.

10 Prenderville JA, Kennedy PJ, Dinan TG, Cryan JF. Adding fuel to the fire: the impact of stress on the ageing brain. Trends Neurosci 2015; 38: 13-25.

11 Moher D, Liberati A, Tetzlaff J, Altman DG. Preferred reporting items for systematic reviews and meta-analyses: the PRISMA statement. PLOS Med 2009; 6: e1000097.

12 Stroup DF, Berlin JA, Morton SC, Olkin I, Williamson GD, Rennie D, et al. Meta-analysis of observational studies in epidemiology: a proposal for reporting. Meta-analysis Of Observational Studies in Epidemiology (MOOSE) group. JAMA 2000; 283: 2008-12.

13 Higgins JPT, Green S (ed). Cochrane Handbook for Systematic Reviews of Interventions: Version 5.1.0 [updated March 2011]. The Cochrane Collaboration, 2011.

14 American Psychiatric Association. Diagnostic and Statistical Manual of Mental Disorders: DSM-5. American Psychiatric Publishing, 2013.

15 Sartorius N. The ICD-10 Classification of Mental and Behavioural Disorders: Clinical Descriptions and Diagnostic Guidelines: 47-51. World Health Organization, 2016.

16 Gough D. Weight of evidence: a framework for the appraisal of the quality and relevance of evidence. Res Pap Educ 2007; 22: 213-28.

17 Wells GA, Shea B, O'Connell D, Peterson J, Welch V, Losos M, et al. The Newcastle Ottawa Scale (NOS) for Assessing the Quality of Nonrandomized Studies in Meta-Analyses. Ottawa Hospital Research Institute, 2014. (http:// www.ohri.ca/programs/clinical_epidemiology/oxford.asp).

18 Sterne JA, Hernán MA, Reeves BC, Savović J, Berkman ND, Viswanathan M, et al. ROBINS-I: a tool for assessing risk of bias in non-randomised studies of interventions. BMJ 2016; 355: i4919.

19 Schwarzer G, Carpenter JR, Rücker G. Chapter 2, Fixed effects and random effect meta-analysis. In Meta-Analysis with $R$ : 28-40. Springer International Publishing, 2015.

20 Schwarzer G, Carpenter JR, Rücker G. Chapter 2.6.1, meta-analysis with survival outcomes. In Meta-Analysis with $R$ (eds R Gentleman, K Hornik, G Parmigiani): 46-8. Springer International Publishing, 2015.

21 R Core Team. R: A Language and Environment for Statistical Computing. R Foundation for Statistical Computing, 2017 (https://www.R-project.org/).

22 Schwarzer G. meta: an R package for meta-analysis. R News 2007; 7: 40-5. 
23 Burke SL, Maramaldi P, Cadet T, Kukull W. Neuropsychiatric symptoms and apolipoprotein E: associations with eventual Alzheimer's disease development. Arch Gerontol Geriatr 2016; 65: 231-8

24 Burke SL, O'Driscoll J, Alcide A, Li T. Moderating risk of Alzheimer's disease through the use of anxiolytic agents. Int J Geriatr Psychiatry 2017; 32: 1312-21.

25 Bruijn RF, Direk N, Mirza SS, Hofman A, Koudstaal PJ, Tiemeier H, et al. Anxiety is not associated with the risk of dementia or cognitive decline: the Rotterdam Study. Am J Geriatr Psychiatry 2014; 22: 1382-90.

26 Gallacher J, Bayer A, Fish M, Pickering J, Pedro S, Dunstan F, et al. Does anxiety affect risk of dementia? Findings from the Caerphilly Prospective Study. Psychosom Med 2009; 71: 659-66.

27 Jessen F, Wolfsgruber S, Wiese B, Bickel H, Mosch E, Kaduszkiewicz H, et al. AD dementia risk in late $\mathrm{MCl}$, in early $\mathrm{MCl}$, and in subjective memory impairment. Alzheimers Dement 2014; 10: 76-83.

28 Lobo A, Bueno-Notivol J, de La Camara C, Santabarbara J, Marcos G, GraciaGarcia $P$, et al. Clinically relevant anxiety and risk of dementia and Alzheimer's disease. J Psychosom Res 2017; 97: 158-9.

29 Palmer K, Berger AK, Monastero R, Winblad B, Bäckman L, Fratiglioni L. Predictors of progression from mild cognitive impairment to Alzheimer disease. Neurology 2007; 68: 1588-602.

30 Stewart JC, Perkins AJ, Hendrie HC, Callahan CM. Depression and anxiety screens as predictors of 8-year incidence of total dementia, Alzheimer's disease, and vascular dementia. Psychosom Med 2015; 77: A3.

31 Terracciano A, Sutin AR, An Y, O'Brien RJ, Ferrucci L, Zonderman AB, et al. Personality and risk of Alzheimer's disease: new data and meta-analysis Alzheimers Dement 2014; 10: 179-86.

32 Wilson RS, Begeny CT, Boyle PA, Schneider JA, Bennett DA. Vulnerability to stress, anxiety, and development of dementia in old age. Am J Geriatr Psychiatry 2011; 19: 327-34.

33 Zilkens RR, Bruce DG, Duke J, Spilsbury K, Semmens JB. Severe psychiatric disorders in mid-life and risk of dementia in late-life (age 65-84 years): population based case-control study. Curr Alzheimer Res 2014; 11: 681-93.

34 Dondu A, Sevincoka L, Akyol A, Tataroglu C. Is obsessive-compulsive symptomatology a risk factor for Alzheimer-type dementia? Psychiatry Res 2015; 225: 381-6.

35 Diniz BS, Butters MA, Albert SM, Dew MA, Reynolds III CF. Late-life depression and risk of vascular dementia and Alzheimer's disease: systematic review and meta-analysis of community-based cohort studies. Br J Psychiatry 2013; 202 329-35.

36 Tapiainen V, Hartikainen S, Taipale $\mathrm{H}$, Tiihonen J, Tolppanen A-M. Hospitaltreated mental and behavioral disorders and risk of Alzheimer's disease: a nationwide nested case-control study. Eur Psychiatry 2017; 43: 92-8.
37 Kuiper JS, Zuidersma M, Oude Voshaar RC, Zuidema SU, van den Heuvel ER, Stolk RP, et al. Social relationships and risk of dementia: a systematic review and meta-analysis of longitudinal cohort studies. Ageing Res Rev 2015; 22: 39-57.

38 Steunenberg B, Twisk JWR, Beekman ATF, Deeg DJH, Kerkhof AJFM. Stability and change of neuroticism in aging. J Gerontol B Psychol Sci Soc Sci 2005; 60 P27-33.

39 Beauquis J, Vinuesa A, Pomilio C, Pavia P, Galvan V, Saravia F. Neuronal and glia alterations, increased anxiety, and cognitive impairment before hippocampal amyloid deposition in PDAPP mice, model of Alzheimer's disease. Hippocampus 2014; 24: 257-69.

40 Marchant NL, Howard RJ. Cognitive debt and Alzheimer's disease. J Alzheimers Dis 2015; 44: 755-70.

41 Barulli D, Stern Y. Efficiency, capacity, compensation, maintenance, plasticity: emerging concepts in cognitive reserve. Trends Cogn Sci 2013; 17: 502-9.

42 McEwen BS. Stress, adaptation, and disease: allostasis and allostatic load. Ann $N$ Y Acad Sci 1998; 840: 33-44.

43 de Lijster JM, DierckX B, Utens EMWJ, Verhulst FC, Zieldorff C, Dieleman GC, et al. The age of onset of anxiety disorders. Can J Psychiatry 2017; 62: 237-46.

44 Bruce SE, Yonkers KA, Otto MW, Eisen JL, Weisberg RB, Pagano M, et al. Influence of psychiatric comorbidity on recovery and recurrence in generalized anxiety disorder, social phobia, and panic disorder: a 12-year prospective study. Am J Psychiatry 2005; 162: 1179-87.

45 Whalley $\amalg$, Dick FD, McNeill G. A life-course approach to the aetiology of lateonset dementias. Lancet Neurol 2006; 5: 87-96.

46 Watson D, Clark LA, Carey G. Positive and negative affectivity and their relation to anxiety and depressive disorders. J Abnorm Psychol 1988; 97 $346-53$

47 do Couto FS, Lunet N, Gino S, Chester C, Freitas V, Maruta C, et al. Depression with melancholic features is associated with higher long-term risk for dementia. J Affect Disord 2016: 202: 220-9.

48 Remes $\mathrm{O}$, Brayne $\mathrm{C}$, van der Linde $\mathrm{R}$, Lafortune $\mathrm{L}$. A systematic review of reviews on the prevalence of anxiety disorders in adult populations. Brain Behav 2016; 6: e00497.

49 Esler M. Mental stress and human cardiovascular disease. Neurosci Biobehav Rev 2017; 74: 269-76. 